\title{
Not All Who Wander are Lost: Fate of Homeless Persons with Mental Illness During COVID-19 Pandemic in North India-Case Series
}

\author{
Agrawal Abhinav (D) Arun Priti · Bala Chandra · Gaga Jatwinder
}

Received: 1 July 2021 / Accepted: 26 October 2021 / Published online: 22 November 2021

(C) The Author(s), under exclusive licence to Springer Nature India Private Limited 2021

\begin{abstract}
Homeless Persons with Mental Illness (HPMI) represent one of the most marginalized communities of the society. The psycho-social impact of the Coronavirus pandemic has been significant on the entire population but causes more suffering in the vulnerable population. During the initial phase of the pandemic in India, strict measures were taken to contain the infection that led to certain unique challenges for HPMI and in their reintegration with society. The series of cases highlight the multiple facets of problems faced and ways to counter them so as to effectively rehabilitate HPMI, with focus on the pandemic at hand. The involvement of a multidisciplinary team, utilization of technological advances and promoting effective liaison with various public sectors are suggested as the way forward.
\end{abstract}

Keywords Homeless · Mental Illness · COVID-19 . Rehabilitation

\section{Introduction}

The COVID-19 pandemic has wreaked havoc all over the world. Since late 2019 the pandemic has

A. Abhinav $(凹) \cdot$ A. Priti - B. Chandra · G. Jatwinder Department of Psychiatry, Government Medical College \& Hospital, Sector 32, Chandigarh 160047, India

e-mail: abhinavagrawal.doc@gmail.com progressively spiraled out of control(WHO Coronavirus (COVID-19) Dashboard |WHO Coronavirus (COVID-19) Dashboard With Vaccination Data, n.d.). To break the initial chain of transmission, nationwide lockdown was announced in India on 24th march 2020. This emergency decision left a lot of people in the lurch, underprepared and clueless. Moreover, the fate of vulnerable communities including homeless and persons with mental illnesses without adequate social support remained neglected despite some commendable efforts [3]. The Universal Declaration of Human Rights defines 'homeless' as those who do not live in a regular residence due to lack of adequate housing, safety, and availability(Singh et al., n.d.). A significant percentage of the country's homeless population suffers from serious and chronic mental disorders $[6,9]$. The process of treating mental illness and eventual rehabilitation in the society which was already a challenging process was mired in new challenges during the pandemic and lockdown $[2,11]$.

During lockdown, HPMI found in Chandigarh were brought by the police to Government Medical College and Hospital (GMCH) which offered emergency and inpatient psychiatric care. The standard operating procedure of keeping all newly admitted persons in isolation and testing for COVID-19 by RTPCR before shifting in general ward was followed. A multidisciplinary team consisting of a Psychiatrist, Clinical Psychologist (CP), Psychiatric Social Worker (PSW) and respective trainees are tasked with management. 
Hospital services for HPMI include waiver of hospital charges and free diet services.

The inpatient facility has separate wings and washrooms for male and female patients. Each wing has large rooms of variable sizes to accommodate 2 to 3 patients with their attendants in a socially distant manner. Recreational activities that took place in a common room have been repurposed to individual bedside activities. A separate room for isolation of COVID-19 suspected individuals is also earmarked.

We present a series of cases highlighting the challenges faced and overcome in management and reintegration of HPMI with the society, during the pandemic and associated lockdown.

\section{Case 1}

A 40 years old female was brought by the Police from a neighboring district of Himachal Pradesh. She had been found roadside in a disheveled condition and was unable to communicate coherently when intercepted by police officials for wandering. She was taken to a regional hospital, wherein she was tested for COVID19 which came out negative and basic medical treatment was given. Whereabouts of her family, home or any means of contacting them were not available.

She was referred to GMCH due to unavailability of comprehensive facilities and was transferred to inpatient Psychiatry ward for further management. PSW trainee arranged clothes and basic amenities including free medicines from the destitute patient's fund. On observation it was noted that initially she did not interact with anyone, did not maintain her activities of daily living and neither participating in any activities. She appeared to understand Hindi and followed basic instructions on persuasion.

After detailed assessment a diagnosis of F. 29 (Unspecified Psychosis not due to a substance or known physiological condition) according to ICD-10 was kept with Borderline Intellectual functioning. Multidisciplinary approach consisted of pharmacological treatment by psychiatrist; behaviour therapy interventions by $\mathrm{CP}$; social skill training, engaging in Activities of Daily Living(ADL), Instrumental Activities of Daily Living(IADL) and recreational activities by PSW. Pharmacological treatment consisted of oral Risperidone optimized to $4 \mathrm{mg}$ over 4 weeks.
Significant improvement in her condition including ADLs, IADLs, communication, understanding regarding illness and need of medication was noted subsequently over a month.

Simultaneous efforts to identify the patient and trace her family were undertaken by PSW team. Technology and innovation came to the rescue. Through biometric identification with the help of Unique Identification Authority of India (UIDAI) ADHAAR card, her identity and address were revealed. She belonged to rural Uttar Pradesh. The 'Pradhan' or head of her native village was contacted who confirmed her identity and subsequently the SHO of the police station of her address was contacted and briefed. The family was fortunately traced. On telephonic consultation with the husband it was revealed that the patient had been mentally ill for many years but due to lack of awareness and resources no psychiatric treatment had been sought. The history suggested an additional diagnosis of Seizure disorder. She had run away from home by train leaving her husband behind about a year back and reached Himachal Pradesh where, she reported to have been surviving by begging and living without proper shelter.

Due to the lockdown restrictions and suspended inter-state public transport, the family expressed inability to come to the hospital. With rigorous telephonic follow-up, liaison between the police officials from Himachal Pradesh who had brought the patient also tasked to take her back and the Police official of her native district in Uttar Pradesh was established. She was successfully reintegrated with her family. Tele-consultation session with the family were initiated to psycho-educate regarding her illness, ensure her compliance and guide them for disability certification through local authorities.

Till 6 month follow up by teleconsultation she is reported to be maintaining well and helps her husband in routine activities. However, she has become non compliant to treatment for last 3 months due to unavailability of free of cost medications in her vicinity. Her husband hasn't yet initiated the process for her disability benefits. 


\section{Case 2}

A 45 year old male was brought by police to the hospital. He had been found stranded on the Chandigarh railway station in a disheveled condition with an orthopedic contraption on his left leg and inability to move without support. He was unable to communicate coherently and admitted in the emergency.

After testing negative for COVID-19, medical and orthopedic interventions were done over the next 2 weeks wherein an external fixator was surgically placed in view of open fracture and secondary infection of left lower limb. During this time he had been confused and was unable to recollect his whereabouts or identification data. He was unable to sleep and did not maintain self care. On physical examination he was emaciated and had multiple tattoos of Hindu religious symbols over his entire body. Whereabouts of her family, home or any means of contacting them were not available. No history of drug use could be elicited.

He was then transferred to inpatient psychiatric care for further management by a multidisciplinary team. On Mental status examination he had formal thought disorder and ideas of persecution. After assessments a provisional diagnosis of F.29 (Unspecified Psychosis not due to a substance or known physiological condition) according to ICD-10 was kept. Pharmacological treatment by psychiatrist, behaviour therapy interventions by $\mathrm{CP}$, providing basic amenities for self care and tracing his family by PSW were initiated. Pharmacological treatment consisted of oral Risperidone optimized to $2 \mathrm{mg}$ over 4 weeks which was subsequently tapered and stopped over next 4 weeks. Liaison with department of orthopaedics was continued, who advised further elective surgical procedures after 3 months. Significant improvement in biological functioning, resolution of formal thought disorder and suspiciousness was noted over the next month. He resumed his self care and interaction with staff as well.

On subsequent interviews he revealed that he had left his home 5 years back and was currently working as a labourer in outskirts of Chandigarh for last 1 year. He had got into an altercation with his employer after which he was injured and left on the station after primary care treatment by them. He reported his native village in Uttar Pradesh and address and desired to be sent back home. Local police authorities of his native village were contacted and a telephonic contact of his family traced. They were willing to take him back but were not able to due to suspension of interstate public transport.

He now had intact judgement and capacity but was unable to travel alone due to physical impairment and lack of funds. A walker to aid him in becoming independently mobile, train ticket and transport to the railway station from the hospital was arranged by our team. He was received at the railway station nearest to his village by the local police authorities as requested by our team and subsequently reunited with his family. Telephonic contact was provided to continue psychiatric consultation as required and family asked to continue treatment for his leg injury at nearby hospital.

Till 6 month follow up by teleconsultation he is reported to be maintaining well with regards to his mental health.He is able to function independently but needs support of the walker for mobility.

\section{Case 3}

A 37 years old female was noted behaving oddly outside the hospital premises and was brought to emergency for evaluation. She was alert and aware of her whereabouts. Clinical interview revealed past history of being admitted in GMCH Psychiatry department in 2019 and she had been rehabilitated to 'Savera'(a sheltered accommodation for abandoned females) after completion of inpatient treatment. She was staying there and maintaining well till a few weeks back when, she had run away from the facility citing the reason of wanting to visit his son during lockdown which wasn't being allowed.

On observation she was excessively cheerful, overtalkative, over-familiar, activity levels were increased and grooming was poor. She was verbally abusive and claimed to be completely alright and full of energy. She was shifted to inpatient psychiatry facility and kept in isolation until after testing negative for COVID-19. The multidisciplinary team was able to trace her previous file records and based on available history and examination a diagnosis of F31 (Bipolar Affective Disorder, current episode Mania) according to ICD-10 was kept. Her pharmacological treatment was reinitiated, behavioral interventions structured and items for self care provided for. Pharmacological treatment consisted of oral Risperidone optimized to 
$4 \mathrm{mg}$, oral Divalpoex Sodium optimized to $1000 \mathrm{mg}$ over 1 week and oral benzodiazepines.

Her rehabilitation posed multiple problems. She was an orphan and had spent most of her adolescence in sheltered accommodation. She had multiple sexual partners and marriages in the past but with no primary source of support at present. She had a young minor son who had been placed in 'Ashiana' (children's home for those in need of care and protection). During episodes of illness her functioning got disturbed and measures to ensure compliance to treatment were inadequate at present.

Following progressive improvement in her manic symptoms, multiple steps were taken to cater to her needs. Advanced level social skill training was initiated. Psycho-education provided using informative model regarding her illness, pharmacological and non-pharmacological treatment and its importance, side effects of medications and misconceptions regarding medications. Telephonic contact was also made possible of the patient with her son once a week. Contact with the social welfare department to shift the patient to 'Nari Niketan'. Follow-ups were scheduled to ensure her adherence to medication.

Till 6 month follow up by teleconsultation she is reported to be maintaining well and has transferred back to 'Savera'. She remains adherent to medication, helps in activities and is in regular telephonic contact with her son.

\section{Discussion}

The aforementioned cases highlight certain under reported practical aspects of management of HPMI during the pandemic. For prompt decision making, ensuring uniform standard of care and unambiguous division of roles, the multidisciplinary team worked in liaison with each other as well as with other departments. The standard operating procedure for the same is presented in a flowchart (Fig. 1).

\section{HPMI and Covid-19 Infection}

Due to lack of information, getting initial history of travel to high risk zones, exposure, past or present symptoms was not possible and testing was conducted pragmatically.
It is generally perceived that HPMI will be more prone to Covid-19 infection due to poor self care, lack of understanding of safety protocols and under nutrition leading to lower immunity yet none was found to be infected [7]. Even though they had other frequently encountered physical co-morbidities. This sample is too small to draw a conclusion that HPMI are not more prone to get infected with COVID-19 than the general population. However until further systematic research is available it is unwise to believe that HPMI are any different from others regarding their propensity for COVID-19 infection. None of them took personal protective measures at presentation and making them understand and adhere to Covid appropriate behavior remained a challenge during their ward stay, as reported by others as well [11].

\section{Role of Technology}

Advancements and availability of technological solutions came to aid in the time of the pandemic.

One such breakthrough was reverse tracing of identity of individuals using Aadhaar data. Once the individuals were in a position to give informed consent, the process was initiated by PSW. The process included contacting local UIDAI office, giving an application for renewal of Aadhaar card and subsequent identity confirmation using biometric data. It is recommended to establish uniform procedure so as to maintain the fine balance between protecting privacy and security as well as aid in identification of HPMI.

Another aid was instantaneous sharing of information and documents with various agencies through E-mail which resulted in more efficient liaison. When the individuals were able to provide details or contacts of their families, they were contacted with consent of the patients. Families after tracing were able to connect with individuals using tele and video calling services. They became instantaneously more cooperative and trusting of the team after direct communication. It is recommended to promote inclusion of such services in routine practice, more so during the pandemic [1].

Tele consultation was initiated after discharge for uninterrupted follow-up with the consent of patients and their family members. Subsequent follow-ups using tele-consultation were pursued yet the digital 


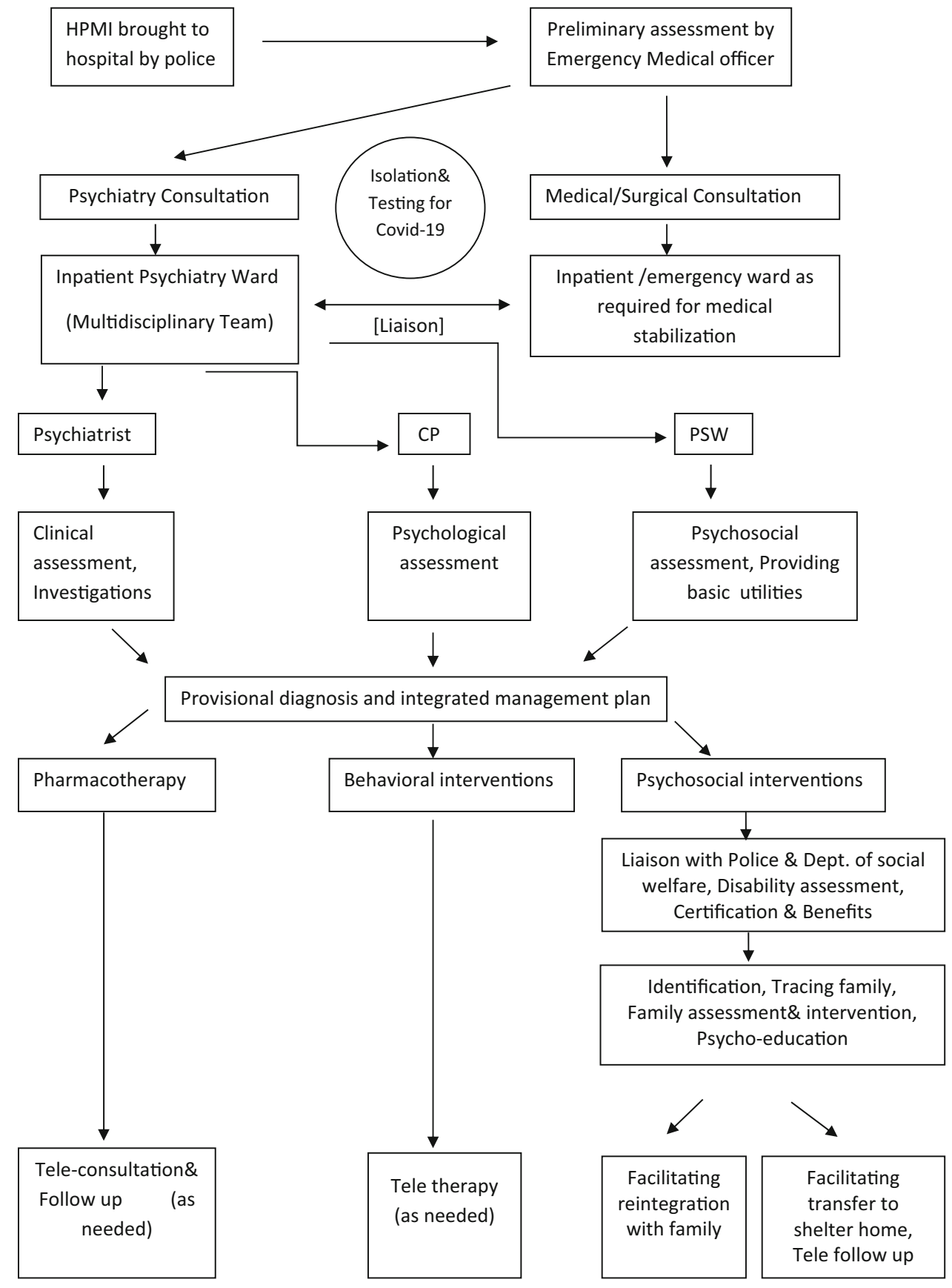

Fig. 1 GMCH model for HPMI during Covid-19

gap remains. None of them had routine access to smart phones which limited sharing of prescriptions.

Past research also endorse the incorporation of newer technologies including search engines like Google, online databases and online messenger services like Whatsapp in the armamentarium of existing traditional modes of communication to expedite reintegration of HPMI [4]. 
Legal and Ethical Challenges

Admission process continues to be challenging for HPMI even with the advent of 'MHCA (2017)' [5]. There is initial absence of advance directives, Nominated Representative (NR), and relatives or caregivers. A suitable person appointed by the Mental Health Review Board or Director of Department of Social Welfare, who are next in line to be appointed, is not available in the acute situation when the police brings the HPMI to us. Hence, the absence of an NR at the time of contact proves an issue for admissions under Sects. 89 and 90. However, another clause, subsect. (4) of Sect. 14, states that 'a person representing an organization under the Societies Registration Act, 1860 or any other law for the time being in force, working for persons with mental illness, may temporarily be engaged by the mental health professional to discharge duties of a NR pending appointment of one by the concerned board'. One possible interpretation of this section is that the resident/doctor who is treating the HPMI could act as the NR till a nomination is received from the Board. This could be a very temporary measure as there would be issues of conflicts of interest. [10]

As per the guidelines of MHCA 2017 [5], serial review of the mental capacity was done and when the individual was found to have mental capacity for decision making regarding admission and treatment his admission would be converted to independent admission. They could then be willingly discharged in the care of respective family members or shifted to residential care homes. Furthermore, MHCA (2017), relieves the judiciary from involvement in admission or discharge. The medical officer "informs" the police officer, who later, in accordance with the act, reintegrates him/her to the family or a less restrictive environment or a government establishment for homeless persons (Sect. 100, Subsection 6) [5].

Hurdles During the Lockdown

Reintegration was delayed and hospital stay prolonged in all three cases by a few weeks due to suspension of public transport. Coordinating with Police officials of multiple states was an arduous task due to lack of clear protocols and not due to lack of compassion and willingness to help. Outdoor day care activities and vocational training services which, are otherwise provided by the department to HPMI had been suspended making rehabilitation more challenging.

Beyond the Pandemic

These cases highlight the need of certain systemic changes that transcend the immediate crisis period. Two of the three cases were eligible for disability certification and despite illness of many years family, hadn't taken initiative due to lack of awareness regarding the process. The outreach of awareness programs regarding the various public health initiatives needs to be extended.

Despite being labeled as HPMI as far as definitions go, two of the three cases had their own home to return to and were just houseless, that too temporarily [10].Identification and reporting of missing persons which eventually helps in reintegrating a large number of HPMI with their families remains technically challenging, possibly due to the digital divide and inadequate infrastructure. A digital centralized registry of missing persons has been initiated by NCRB in 2020, yet its utilization and efficacy remains to be seen and promoted [8].

\section{Conclusion}

The aforementioned three cases reflect the complexities of the mental illness and homelessness spiral. With lack of adequate structural and functional facilities for the advancement of community-based services, reintegration with family and community remains especially challenging for service providers during these testing times. Persistent efforts, increasing our proficiency and reliance on digital solutions with systemic changes appear to be the way forward.

Funding This research did not receive any funding from any public, private or non-profit organization.

\section{Declarations}

Conflict of interest The authors declared that they have no conflict of interest. 


\section{References}

1. Chevance A, Gourion D, Hoertel N, Llorca PM, Thomas P, Bocher R, Moro MR, Laprévote V, Benyamina A, Fossati P, Masson M, Leaune E, Leboyer M, Gaillard R. Ensuring mental health care during the SARS-CoV-2 epidemic in France: a narrative review. L'Encephale. 2020;46(3): 193-201. https://doi.org/10.1016/j.encep.2020.04.005.

2. Gopika CG, Vani P, Ithal D, Jayakumar C. Homeward bound; reintegrating a homeless mentally III person and his family during the COVID-19 pandemic lockdown. Indian J Soc Psychiatr. 2021;37(1):115. https://doi.org/10.4103/ IJSP.IJSP_300_20.

3. Gowda GS, Chithra NK, Moirangthem S, Kumar CN, Math SB. Homeless persons with mental illness and COVID pandemic: collective efforts from India. Asian J Psychiatr. 2020;54:102268. https://doi.org/10.1016/j.ajp.2020.102268.

4. Gowda GS, Telang A, Reddy Sharath C, Gregor Issac T, Haripriya C, Shivalli Ramu P, Bada Math S. Letter to the editor use of newer technologies with existing service for family reintegration of unknown psychiatric patients: a case series. Asian J Psychiatr. 2017. https://doi.org/10.1016/j. ajp.2017.10.022.

5. MHCA 2017 - ACT. (n.d.). Retrieved October 16, 2021, from http://mhca2017.com/index.php/act.

6. Moorkath F, Vranda M, Naveenkumar C. Lives without roots: Institutionalized homeless women with chronic mental illness. Indian J Psychol Med. 2018;40(5):476-81. https://doi.org/10.4103/IJPSYM.IJPSYM_103_18.
7. Naik SS, Gowda GS, Shivaprakash P, Subramaniyam BA, Manjunatha N, Muliyala KP, Reddi V, Kumar CN, Math $\mathrm{SB}$, Gangadhar BN. Homeless people with mental illness in India and COVID-19. Lancet Psychiatry. 2020;7(8):e51-2. https://doi.org/10.1016/S2215-0366(20)30286-8.

8. National Crime Records Bureau. (n.d.). Retrieved June 30, 2021, from https://ncrb.gov.in/en.

9. A comprehensive report on chandigarh homeless survey 2019. 2020. http://mcchandigarh.gov.in/sites/default/files/ Chandigarh\%20Homeless\%20Survey\%20Report.pdf

10. Swaminath G, Enara A, Rao R, Kumar K, Kumar CN. Mental healthcare act, 2017 and homeless persons with mental illness in India. Indian J Psychiatry. 2019;61(Suppl 4):S768-72. https://doi.org/10.4103/psychiatry.Indian JPsychiatry_117_19.

11. Vranda MN, Ranjith J, Febna M, Sreelakshmi PS. Reintegration of homeless patients with mental illness (HPMI) in the community - challenges faced during COVID-19 pandemic. Indian J Psychol Med. 2021. https://doi.org/10.1177/ 0253717621999575.

12. WHO Coronavirus (COVID-19) Dashboard | WHO Coronavirus (COVID-19) Dashboard With Vaccination Data. (n.d.). Retrieved May 23, 2021, from https://covid19. who.int/.

Publisher's Note Springer Nature remains neutral with regard to jurisdictional claims in published maps and institutional affiliations. 